\title{
OUTCOME OF INFERONASAL CONJUNCTIVAL AUTOGRAFT IN PTERYGIUM SURGERY
}

\author{
Pragati Gautam Adhikari, Sagun Narayan Joshi
}

Department of Ophthalmology, Maharajgunj Medical Campus, Institute of Medicine, Tribhuvan University, Maharajgunj, Kathmandu, Nepal

\section{ABSTRACT}

This study was done to evaluate the outcome of pterygium excision with inferonasal conjunctival autograft at a tertiary eye care centre. Retrospective analysis of medical records of primary pterygia patients operated by a single surgeon between 2017 to 2020 were analyzed. A total of 43 patients who met the inclusion criteria were included in the study. The demographic variables, along with size of pterygium and recurrence over a period of six month follow up was noted. The mean age of patients was 46.97 years (29-74 years). The mean size of pterygium was 3.17 $\mathrm{mm}$. Recurrence was seen in 3 eyes over a period of 6 months. Graft edema was observed in 11 patients and graft hemorrhage along with congestion was seen in 8 cases which resolved over a 3 weeks follow up period. Mild conjunctival scarring was seen over donor area in 5 of the eyes. Pterygium excision with inferior conjunctival autograft is an effective alternative technique to superotemporal autograft technique.

\section{KEYWORDS}

Autograft, conjunctival, inferonasal, Nepal

Received on: August 28, 2021

Accepted for publication: November 25, 2021

\section{CORRESPONDING AUTHOR}

Dr. Pragati Gautam Adhikari,

Lecturer,

Department of Ophthalmology,

Maharajgunj Medical Campus, Institute of Medicine,

Tribhuvan University, Maharajgunj, 44600, Nepal

Email: pragatiadhikari.pg@gmail.com

Orcid No: https://orcid.org/0000-0003-4812-2456

DOI: https://doi.org/10.3126/nmcj.v23i4.42223 


\section{INTRODUCTION}

Pterygia are wing-shaped conjunctival disorder extending from the bulbar conjunctiva onto the cornea which occurs predominantly on the nasal limbus. The pathogenesis of pterygia is not well understood. Epidemiological factors influencing pterygium development have been suggested (chronic sun exposure, age, or dry weather. $^{1-5}$ The surgical excision is the main treatment method of pterygium. The mainstay of management is surgical excision but prevention of recurrence is the main challenge, which has been estimated to be as high as 30$80 \%$ in simple excision. ${ }^{6}$ Surgical techniques include bare sclera excision, conjunctival autograft, conjunctival transpositional flap, and amniotic membrane grafting. ${ }^{7,8}$

Auto graft transplantation following pterygium excision presents the advantage of adding the function of the limbus, which improves corneal healing. ${ }^{9}$ Conjunctival auto graft from the inferior bulbar conjunctiva leaves the superior bulbar conjunctiva intact for further glaucoma filtering surgery if needed in the future. Therefore, this study aims to find out the outcome of pterygium surgery with inferonasal conjunctival graft in patients over six-month duration after the surgery.

\section{MATERIALS AND METHODS}

Data from all primary pterygium excision with inferonasal conjunctival autograft performed at the BP Koirala Lions Centre of Ophthalmic studies by a single surgeon from January 2017 to December 2020, were retrospectively analyzed from the record files after taking consent from department. Preoperative data collection included age, sex, visual acuity, ocular examination and surgical history. Postoperatively, visual acuity, complications were noted in cases with follow up of at least 6 months. Based on the involvement of pterygium over the cornea they were graded as follows; Grade 1: crossing limbus; Grade 2: midway between limbus and pupil; Grade 3: reaching up to pupillary margin; and Grade 4: crossing pupillary margin. All the surgeries were performed by a single surgeon. All the surgical procedures were performed under peribulbar anesthesia. The technique of conjunctival autografting involved closure of the conjunctival defect following pterygium excision with a free conjunctival autograft harvest from the infer-nasal bulbar conjunctiva. First, the head and the body of the pterygium were excised. The remaining subconjunctival degenerative part of the pterygium was excised with Westcott scissors. The polishing and smoothing of the scleral and corneal bed and limbal surfaces were performed using hockey-stick knife. Cautery was applied to any bleeding vessels. The autograft was taken from inferonasal bulbar conjunctiva and sutured to the underlying sclera at the limbus and the cut conjunctiva edges by interrupted 8-0 vicryl sutures. Postoperatively, artificial tears, topical steroids, and antibiotic eye drops were used, initially four times a day for one week. Topical steroids were tapered over 4-6 weeks depending on the degree of inflammation and the postoperative course. SPSS version 20 was used for statistical analysis. Rank correlation was done to see correlation between pterygium size, age, gender and occupation of patient respectively.

\section{RESULTS}

The mean patient age was $46.97 \pm 15$ years (range, 29-74 years). The males were 19 and female were 24. There was no correlation between gender and size of pterygium (Rank correlation, $\mathrm{p}=0.753$ ) as well as no correlation between gender and grade of Pterygium (Rank correlation, $\mathrm{p}=0.150$ ).

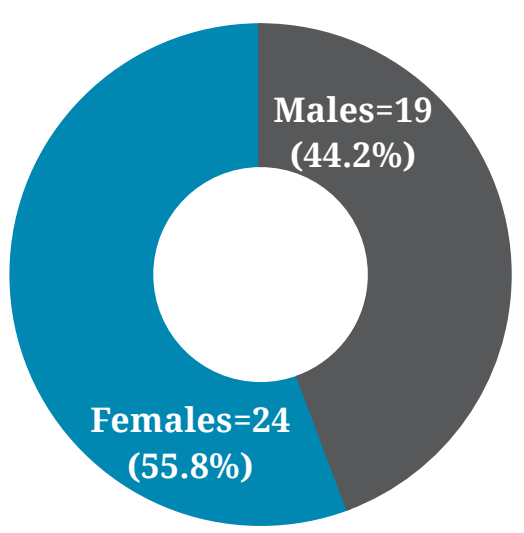

Fig. 1: Distribution of Gender

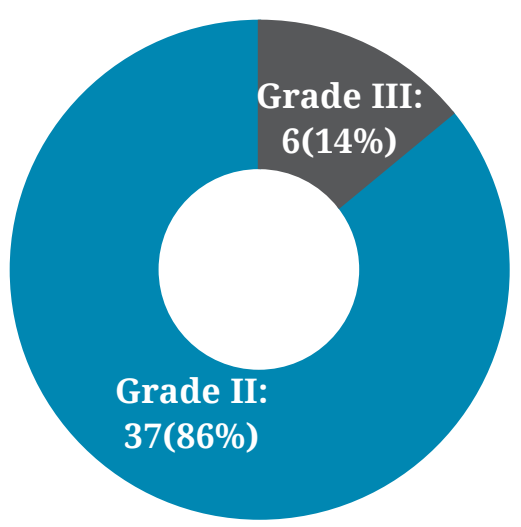

Fig. 2: Distribution of grade of Pterygium 
The mean size of pterygium was $3.17 \mathrm{~mm}$. The majority of eyes had grade II (37: 86\%) pterygium and 6 eyes (14\%) had grade III pterygium. There was no correlation between grade of pterygium and age (Spearman Rank correlation, $\mathrm{p}=0.070$ ). The size of pterygium showed positive correlation with grade of pterygium (Rank correlation, $\mathrm{p}<0.001$ ) as seen in Fig. 2.

Around 23 of the patients had outdoor jobs where as 20 of the patients stayed at home or had job that required them to be indoors. No correlation was seen between size of pterygium and occupation. (Rank correlation, $p=0.222$ ) as well as between grade of pterygium and occupation (Fig. 3).

\section{Distribution of Occupation}

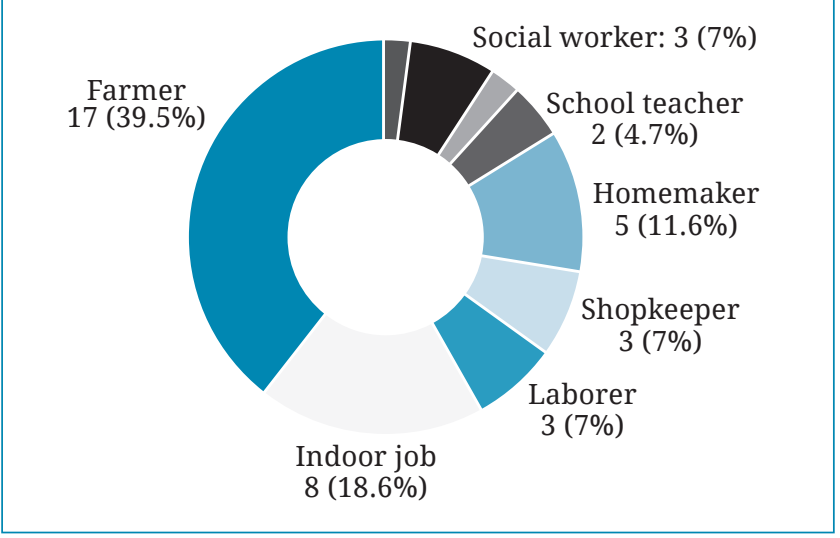

Fig. 3: Distribution of Occupation

The most common complication following pterygium surgery with infero-nasal conjunctival autograft was graft edema observed in 11 patients followed by graft hemorrhage along with congestion in 8 cases which resolved over 3 weeks follow up. Other complications were mild conjunctival scarring seen over donor area in 5 of the eyes and graft retraction in one eye. Recurrence was seen in 3 (6.9\%) eyes over period of 6 months follow up. The most common reason for surgery was for symptomatic relief reason $(n=30)$ followed by cosmetic reason $(n=8)$ and fear of loss of vision $(n=5)$.

\section{DISCUSSION}

The main treatment of pterygium is surgical. There are many surgical techniques, including pterygium excision with bare sclera, conjunctival autografting, amniotic membrane grafting, and adjuvant use of mitomycin C. ${ }^{10,11}$ However, recurrence-free surgery for pterygium continues to present a challenge. The numerous different techniques that exist for the surgical treatment of pterygium implies that a single approach is universally successful. The use of conjunctival autograft has been widely used in pterygium surgery since first reported in 1985. Currently, the most widely used procedure is pterygium excision with conjunctival autograft. A number of studies have graft from the superior bulbar conjunctiva had showed that conjunctival autografting has a low recurrence rate. ${ }^{8,12}$ However, studies on infero-nasal autograft are limited.

Postoperative recurrence is the most prominent undesirable effect in the pterygium surgery. The risk factors of pterygium recurrence are not known precisely, but a number of factors such as pterygium type, age of patient, environment, excision of a recurrent pterygium, and surgical technique may be responsible. The recurrence rate varies according to the technique used, and it has been reported in different rates. The recurrence with conjunctival autograft technique was reported to be $3 \%-28 \% .^{7,13-15}$ It was reported to be $5.3 \%$ in the primary pterygium group by Kenyon. ${ }^{13}$ Some studies which have reported autografting from superior or inferior sites in primary pterygium cases showed no significant difference in recurrence rate. ${ }^{16,17}$ Pterygium excision followed by a superior conjunctival autograft has a low recurrence rate, it could compromise the site for future filtration surgery. ${ }^{18}$

The recurrence of the pterygium usually occurs during postoperative first six months and in ours too these recurrences occurred over 6 month follow up. Recurrence rate of the present study was $6.9 \%$ in infero-nasal conjunctival autograft, which is comparable with what is described in the literature regarding superior conjunctival autografting for pterygium surgery as well as with inferior conjunctival conjunctival autografting. Recurrence rate of the present study was $6.9 \%$ in infero-nasal conjunctival autograft, which is comparable with what is described in the literature regarding superior conjunctival autografting for pterygium surgery as well as with inferior conjunctival conjunctival autografting. In a similar study done by Shrestha et al in Nepal using infero-nasal conjunctival autograft, have reported it to be $4 \%$ in primary pterygium. ${ }^{19} \mathrm{~A}$ study comparing inferior conjunctival graft to that of superior had confirmed the benefits of using inferior conjunctival graft over superior conjunctival graft with regard to postoperative discomfort; less postoperative discomfort for patients with primary pterygium and 5\% 
recurrences rate that occurred within 6 months after surgery. ${ }^{20}$

Study done by Wong reported it to be $18.2 \%$ with infero-limbal conjunctival graft in recurrent pterygium. ${ }^{21}$ A study comparing autografting from superior or inferior sites in primary pterygium cases showed no significant difference in recurrence rate, but in the event of recurrent pterygia, autografting from the inferior site resulted a higher likelihood of recurrence.

Though being male was considered a risk factor for pterygium occurrence, our study showed no correlation with gender. With age also no correlation was found. Most of our patient were either farmers or involved in outdoor activity. Many population-based studies suggest that ultraviolet light exposure due to outdoor occupation is a major risk factor for the development of pterygium. Other factors associated with pterygium development are age, and having dry eyes. ${ }^{22}$

The most common indication for surgery in our study was symptomatic pterygium which is similar to two other studies. ${ }^{13,19}$ Beside this, the other indications were cosmetic reason and fear of loss of vision. Comfort after pterygium surgery is also an important factor, while considering surgey. Inferior conjunctival autografting was also associated with less discomfort postoperatively irritation. ${ }^{23}$ However, being a retrospective nature of the study we could not look into this matter.

Conjunctival autografting is associated with many complications including scarring at donor site, graft edema, graft necrosis, graft displacement or loss, inclusion cysts, subconjunctival hematoma, Tenon's granuloma, giant papillary conjunctivitis, corneal narrowing, and Dellen ulcers ${ }^{24}$.
Graft edema (25.5\%) was the most common complication seen in our study followed by congestion with hemorrhage (18.6\%). Minimal scarring was seen in $11.6 \%$ of the patients. However, there was no loss of graft or dellen formation or inclusion cyst formation. Harvesting the inferior bulbar conjunctiva is thought to be more technically difficult in inferior autograft technique along with risk of symblepharon formation with this technique. However, we did not find such occurrence in our study. In a study done comparing superior and inferior conjunctival autografts with fibrin glue in management of primary pterygium, subconjunctival scarring was seen in 3 cases of the inferior group (16.6\%) with one case developing symblepharon (5.5\%). ${ }^{16}$ While in a study done by Shrestha et al. found conjunctival scarring rate at the donor site to be $8 \% .{ }^{19}$ The infero-conjuctival autograft for pterygium surgery seems a promising approach as concluded by few studies. ${ }^{25-27}$

The main limitation of our study was that it was a retrospective study and follow up period was also less. A large multicentric longitudinal study needs to be done to validate the effectiveness of inferior conjuctival autogfraft technique in pterygium surgery.

In conclusion, pterygium excision with inferior conjunctival autograft is an effective alternative technique to superior temporal autograft technique. This technique ensures that the conjunctiva of superior site can be preserved for future glaucoma surgery especially when there is the presence, or risk, of glaucoma. This technique also reported a less recurrence compared to the supero-temporal technique.

Conflict of interest: None

Source of research fund: None

\section{REFERENCES}

1. McCarty CA, Fu CL, Taylor HR. Epidemiology of pterygium in Victoria, Australia. Brit J Ophthalmol 2000; 84: 289-92.

2. Marmamula S, Khanna RC, Rao GN. Populationbased assessment of prevalence and risk factors for pterygium in the South Indian state of Andhra Pradesh: The Andhra Pradesh eye disease study. Invest Ophthalmol Vis Sci 2013; 54: 5359-66.

3. Nangia V, Jonas JB, Nair D, Saini N, Nangia $\mathrm{P}$, Panda-Jonas S. Prevalence and associated factors for pterygium in rural agrarian Central
India. The Central India Eye and Medical Study. PLoS One 2013; 8: 1-6.

4. Saw SM, Tan D. Pterygium: Prevalence, demography and risk factors. Ophthalmic Epidemiol 1999; 6: 219-28.

5. Bradley JC, Yang W, Bradley RH, Reid TW, Schwab IR. The science of pterygia. Brit J Ophthalmol 2010; 94: 815-20.

6. Salman AG, Mansour DE. The recurrence of pterygium after different modalities of surgical treatment. Saudi J Ophthalmol 2011; 25: 411-15. 
7. Mohammed I. Treatment of pterygium. Ann Afr Med 2011; 10: 197-203.

8. Clearfield E, Muthappan V, Wang X, Kuo IC. Conjunctival autograft for pterygium. Cochrane Database Syst Rev 2016; $2: 65$.

9. Masters JS, Harris DJ. Low recurrence rate of pterygium after excision with conjunctival limbal autograft: A retrospective study with long-term follow-up. Cornea 2015; 34: 1569-72.

10. Yu JF, Song Y, Wu Y. Efficacy analysis of three surgical methods in treatment of pterygium. Int'l Eye Sci 2013; 13: 601-2.

11. Foroutan A, Beigzadeh F, Ghaempanah MJ et al. Efficacy of autologous fibrin glue for primary pterygium surgery with conjunctival autograft. Iran J Ophthalmol 2011; 2339-47.

12. Nazullah Shah A, Ahmed M, Baseer A, Marwat SK, Saeed N. Recurrence rate of pterygium: A comparison of bare sclera technique and free conjunctival autograft. J Med Sci 2010; 18: 36-47.

13. Kenyon KR, Wagoner MD, Hettinger ME. Conjunctival autograft transplantation for advanced and recurrent Pterygium. Ophthalmol 1985; 92: 1461-70.

14. Aslan L, Aslankurt M, Aksoy A, Özdemir M, Yüksel E. Comparison of wide conjunctival flap and conjunctival autografting techniques in pterygium surgery. J Ophthalmol 2013; 2013: 1-5.

15. Alpay A, Ugurbaş SH, Erdogan B. Comparing techniques for pterygium surgery. Clin Ophthalmol 2009; 3: 69-74.

16. Bor'i A, Elmarakby MA. Superior versus inferior conjunctival autograft using $F$ fibrin glue in management of primary pterygium: Clinical and histopathological results. J Clin Exp Ophthalmol 2016; 07: 1-6.
17. Li W, Lou Y, Wang B. Recurrence rate with inferior conjunctival autograft transplantation compared with superior conjunctival autograft transplantation in pterygium surgery: a metaanalysis. BMC Ophthalmol 2021; 21: 131.

18. Broadway DC, Grierson I, Hitchings RA. Local effects of previous conjunctival incisional surgery and the subsequent outcome of filtration surgery. Am J Ophthalmol 1998; 125: 805-18.

19. Shrestha A, Shrestha A, Bhandari S et al. Inferior conjunctival autografting for pterygium surgery: An alternative way of preserving the glaucoma filtration site in far Western Nepal. Clin Ophthalmol 2012; 6: 15-9.

20. Chen Q, Li Y, Xu F et al. Comparison of Inferior and Superior Conjunctival Autograft for Primary Pterygium. Curr Eye Res 2015; 40: 786-91.

21. Wong AKK, Rao SK, Leung ATS, Poon ASP, Lam DSC. Inferior limbal-conjunctival autograft transplantation for recurrent pterygium. Indian J Ophthalmol 2000; 48: 21-4.

22. Singh SK. Pterygium: epidemiology prevention and treatment. Com Eye Health 2017; 30: S5-S6.

23. Syam PP, Eleftheriadis H, Liu CSC. Inferior conjunctival autograft for primary pterygia. Ophthalmol 2003; 110: 806-10.

24. Dandekar P, Patyal S. Effectiveness of inferior conjunctival autograft in primary pterygium Surgery. J Dent Med Sci 2017; 16: 26-33.

25. Saoji C, Muley S, Daigavane S. Outcome of infero temporal suture less and glue free conjunctival autograft in patients with pterygium at a tertiary care hospital of Vidarbha region. Indian J Forensic Med Toxicol 2020; 14: 6297-301.

26. Kim S, Yang Y, Kim J. Primary pterygium surgery using the inferior conjunctival transposition flap. Ophthal Surg Lasers 1998; 29: 608-11. 